УДК 792

DOI: $10.17223 / 22220836 / 34 / 5$

\title{
Д.Г. Самитов
}

\section{ДВИЖЕНИЕ «МАЛЫХ» И ХУДОЖЕСТВЕННЫХ ТЕАТРОВ США. ТЕАТР «ГИЛД»}

\begin{abstract}
В современный период развития российского театра актуально изучение опыта деятельности «малых» и художественных театров США, которые развивали национальную драматургию, режиссуру и актерское творчество. Театр «Гилд» является ярким примером демократического художественного театра европейского типа. Попытки создания системы репертуарного театра и постоянной труппы, абонементы, попечительские советы внесли важный вклад в организационную структуру в противовес коммерческим коллективам.

Ключевые слова: «малые» театры, художественные театры, Бродвей, театр «Гилд», Тереза Хелберн.
\end{abstract}

Движение некоммерческих театров США родилось в 10-30-е гг. ХХ в. с движения «малых» и художественных театров.

Об этом говорили и писали, в частности, Ф. Фергюссон, один из самых ярких теоретиков и историков американской сцены. «Новые движения в нашем театре, - писал он, - всегда начинаются в более или менее явном противоречии к вкусам, стандартам и условиям работы индустрии развлечений. «Малые» театры стремились дать альтернативу Бродвею во всем, за что он стоял, то же было и с „социально-сознательным“ театром 30-х гг., то же происходит и сейчас в некоммерческом движении» [1. Р. 5-6].

Некоммерческое театральное движение имеет свои причины, задачи, силы и даже формы. Но главное в нем - в сознательном противодействии и отказе от коммерциализма Бродвея и в приоритете художественных и творческих задач.

Не все американские исследователи согласны с такой постановкой вопроса. Так, например, автор наиболее обширной истории некоммерческих театров Стюарт Литтл вообще не уделяет внимания этой проблеме [2]. С другой стороны, Х. Гринбергер последовательно ведет историю некоммерческих театров от движения „малых“, художественных и «левых» театров межвоенного десятилетия [3]. Автор солидной работы о региональных театрах «По ту сторону от Бродвея: поиск постоянного театра» Дж. Новик также подчеркивает, что основоположниками некоммерческого движения стали «любительские „малые“ театры, появившиеся в различных частях страны, особенно в двадцатые годы, полные высоких надежд и дерзких манифестов, чтобы представить авангардные драмы дня» [4]. К данному мнению присоединяется автор известной книги «Менеджмент в американском театре» С. Ленгли. Он, в частности, пишет: «,Малые“ театры можно назвать почитаемыми прототипами значительного количества некоммерческих трупп. Они доказали, что непрофессиональный серьезный театр может существовать в мире капитала театрального коммерциализма, и что самое важное, эти организации внесли огромный вклад в развитие искусства и театрального мастерства. Некоторые 
из них были сезонными и строили свою деятельность скорее на оптимизме, чем на деньгах... Любое новаторство всегда основывается на любительском уровне, и этот дух более пронизан свободой, чем обстановка в ведущей коммерческой компании» [5. Р. 115].

Таким образом, общественное движение «за искусство высокой художественности, общественной значимости и демократичности» в противовес коммерциализированному развлекательному Бродвею появилось в США еще в начале XX в. и достигло развития в 1910-1930-е гг. Театры этого типа стали называться «малыми». Х. Гринбергер считает все созданные тогда театры некоммерческими и склонен относить зарождение движения к 1905 г.: «Первые звуки, издаваемые офф-Бродвеем, как несогласие с политикой существующего театра, прозвучали в свободных радикальных пьесах, поставленных Джулиусом Хоппом в Прогрессивном Сценическом Обществе («Progressive Stage Society») в Нью-Йорке... Однако новое явление не стало полностью самостоятельным до начала следующего десятилетия» [3. Р. 3].

Взгляды нового поколения на театр и его задачи лучше всего выразил У.П. Итон, активный деятель движения «малых» театров и его теоретик. В книге «Американская сцена сегодня» [6] он изложил их, связав театр с общим процессом развития реализма в искусстве.

«Движение „малых“ театров, начавшееся в начале XX в., затем пережило подъем в 1914-17 гг. и было прервано вступлением США в Первую мировую войну. После заключения мира в 1918 г. наблюдалась новая активизация деятельности „малых» театров и увеличение их количества. С середины 20-х годов, когда Америка переживала период „просперити“, движение „малых“ театров в связи с общим снижением активности масс претерпело некоторый кризис, чтобы достигнуть высшего подъема в тридцатые годы».

Борцы за новый театр прекрасно понимали, что изменение качества американского театра возможно лишь с преобразования его организационной основы, исключения зависимости театра от коммерции. Поэтому весьма влиятельным было направление, пытавшееся под руководством основателя театрального обучения в американских университетах профессора Д.П. Бейкера добиться создания в США государственного театра. К сожалению, достичь этого так и не удалось.

В конце Великой депрессии и в годы Первой мировой войны художественные и «малые» театры предшествовавших десятилетий практически прекратили свое существование. Единственными представителями театрального искусства в годы войны и после нее оставались бродвейские театры. Все они были коммерческими и представляли собой особую отрасль американской индустрии зрелищ.

Продюсеры коммерческих театров нанимают творческий состав, исходя из стандартов, которые будут одобрены уже заранее изученным и апробированным средним зрительским вкусом, за исключением двух-трех известных исполнителей и «звезды». Бродвею в соответствии с его природой откровенно чужды волнение и забота о духовных и интеллектуальных потребностях артиста. Это никаким образом нельзя перевести в прибыль, а раз так, то гораздо проще заключить контракт с новым актером в строгом соответствии с его амплуа и не тратить время и тем более средства на творческое развитие и совершенствование артиста. Поэтому пока зрители продолжают довольство- 
ваться коммерческой продукцией, многое из того, что относительно дешево, поверхностно будет продолжать видеть свет огней бродвейских театров. Публика требует удовлетворения своих желаний, режиссер стремится отвечать требованиям публики, критики же Нью-Йорка пытаются объяснить эту ситуацию. Газета «Нью-Йорк Таймс» и другие ежедневные газеты регулярно на утро после каждой премьеры печатают рецензии на новый спектакль. В отличие от европейских стран, да, пожалуй, и большинства других городов США, где мнение театрального обозревателя расценивается как частный взгляд на художественный процесс или отдельное его проявление, отзыв критика нью-йоркской ежедневной газеты - это вердикт судьи и нередко беспощадный приговор или откровенная реклама.

Участники движения «малых» театров подходили к театру как явлению общественному и художественному. Они исходили из положения о первостепенной роли драматургии в театре. Поэтому они так резко выступали против репертуара коммерческих театров, понимая, что создание нового театра нужно начинать с создания национальной драматургии.

Главнейшей целью деятельности «малых» театров была постановка художественно ценных драматических произведений, создание национального театра, свободного от коммерческих принципов. В них начала формироваться новая реалистическая школа актерской игры, отвергавшая систему «звезд». Все движение испытывало сильнейшее влияние европейских свободных и художественных театров.

К 1920 г. в США насчитывалось уже около 200 подобных театров, в основном любительских. Среди них выделялись несколько значительных творческих коллективов, чья деятельность сыграла важную роль в развитии всего американского театра.

В первую очередь следует назвать театр «Гилд». Он был создан в 1918 г. как профессиональный коллектив на основе реорганизации своего любительского предшественника - «Актеров Вашингтон сквер». Он стал первым профессиональным театром среди любительских «малых» театров. Это был и первый кооперативный театр, где все его участники - актеры, режиссеры и менеджеры - были равноправными партнерами, получавшими минимальную зарплату и определенный процент от доходов, которые складывались от поступлений от продажи билетов. Театр имел общественный совет. Он состоял из людей различных профессий и содействовал выбору пьес. Это, видимо, был своеобразный прототип попечительских советов, которые появятся в некоммерческих театрах после Второй мировой войны.

«Гилд» полнее, чем другие участники движения «малых» театров, сумел воплотить идеал художественного просветительского, демократического театра европейского типа. Это определялось принципами широты и качественности драматургии, верно и творчески раскрываемых в постановке, стремлением создать постоянную труппу и ввести систему меняющегося репертуара, завоевать широкие слои зрителей. Первым в Америке «Гилд» ввел в драматическом театре подписку на абонементы и большое внимание уделял работе со своими подписчиками, желающими увидеть все премьеры сезона. Директор «Гилда» Т. Хелберн подчеркивала: «...мы существуем для публики, но не публики коммерческого театра, впадающей в восторг от фарса, мелодрамы, 
комической оперы. Зритель ждет настоящих, глубоких и прекрасных произведений, способных его обогатить» [7].

«Гилд» старался создать постоянную труппу, ввести репертуарную систему и ставить произведения не только мировой, но и национальной драмы. Репертуар его всегда оставался достойным самых высоких похвал, хотя встречались и произведения второго плана. Но руководство «Гилда» стремилось так его сбалансировать, чтобы выдающиеся произведения, которые были непривычны для американской сцены и не могли рассчитывать на большую популярность, ставились за счет более доступных для зрителей комедий, чей финансовый успех компенсировал затраты на вышеуказанные пьесы. Поэтому в театре, особенно в ранний период, ставились и классика, и современные, и экспериментальные произведения. Именно «Гилду» принадлежит честь первых постановок таких пьес Б. Шоу, как «Дом, где разбиваются сердца», «Назад к Мафусаилу», ряда пьес американских драматургов Ю. О'Нила, Э. Раиса, С. Хоуарда, Д.Г. Лоусона и др.

Гораздо хуже дело обстояло с введением репертуарной системы и постоянной труппы. Хотя эти принципы и упоминались как основные в Манифесте театра, но их осуществление оказалось чрезвычайно трудным и в результате так и не состоялось, хотя театр приложил немало сил, чтобы добиться этого. Трудности начались с самого зарождения театра. В 1919 г. в «Гилде» была поставлена очень удачно пьеса Д. Сент-Эрвина «Джон Фергюссон». Успех был настолько велик, что сразу встал вопрос: продолжать показывать этот спектакль серийно, пока будет ходить публика и, таким образом, отказаться от репертуарного принципа работы, либо остаться ему верным и работать над следующим спектаклем. Художественные максималисты во главе с постановщиком О. Дунканом требовали верности принципу репертуарности. Но победили прагматики - спектакль показывался 60 раз подряд. Это имело далеко идущие последствия: «Гилд» сразу отказался не только от репертуарной системы, но и от принципа постоянной труппы, так как для подготовки следующего спектакля пришлось набрать других актеров.

Однако дальнейшая деятельность театра показала, что если он хочет развиваться как художественное учреждение, то ему необходимо иметь постоянную труппу, чтобы двигаться вперед и совершенствоваться, а не начинать работу над каждой новой пьесой с обучения актеров. Поэтому руководство коллектива все время стремилось к созданию труппы.

Наконец, в конце 20-х гг., в самый пик популярности театра, когда он сумел привлечь около 30 тыс. держателей абонементов, построить собственное здание, организовать постоянные выступления в ряде ближайших городов, очередь дошла и до создания труппы, вернее, ее ядра. В сезон 1926/27 года ненадолго была создана постоянная труппа из 10 артистов, среди которых можно назвать Э. Уэстли, Л. Фонтанн, А. Ланта, Д. Диггса, Э. Робинсона, Г. Трэверса. В театре вырос и свой крупный режиссер Ф. Неллер. Постоянная труппа, полурепертуарная система быстро принесли свои плоды. Артисты, пришедшие в театр неопытными и неизвестными, развили и укрепили свои дарования, создав творческий ансамбль.

К концу 20-х гг. начинается постепенное перерождение «Гилда». Коллектив все больше переходит на позиции коммерческого театра. Театру так и не удалось реализовать своих надежд, а также потенциал постоянной труппы. 
Став крупным театром, он не мог иметь перспектив для развития своего художественного творчества. Главной причиной этого была невозможность добиться финансовой стабильности при большом размахе деятельности.

«Гилд» был одним из первых коллективов, который показал неспособность художественной эволюции театра без постоянной материальной поддержки. Еще в 1921 г. Т. Хелберн отмечала, что «в театре была осуществлена попытка обвенчать искусство и бизнес, ради чего пришлось пойти на компромиссы» [7. Р. 12]. Многие исследователи определяли такие идеи «Гилда» как утопические, находящиеся в противоречии с бродвейскими. Они констатировали явный конфликт между двумя типами театров - коммерческим и художественным. Известный критик Б. Аткинсон, высоко ценивший «Гилд», тем не менее именует его участников «утопистами, не интересовавшимися тем, как заработать деньги» [8. С. 209].

Но руководители «Гилда» не желали быть утопистами и решили спасти театр от финансовой катастрофы. Но за счет чего?

С начала 30-х гг. «Гилд» отказывается от провозглашенных ранее принципов, все более верно следуя бродвейской практике, отличаясь от других бродвейских антреприз лишь большей художественной требовательностью. Пример истории этого коллектива подтверждает невозможность создания на Бродвее художественного театра с постоянной труппой и меняющимся репертуаром.

Среди признанных продюсерами Бродвея в послевоенные годы, пожалуй, единственным исключением был театр «Гилд». Именно эта театральная организация, существовавшая с 1918 г., выросла из «малого» театра «Вашингтон Сквер Плейерз». Но почти через тридцать лет «Гилд» почти утерял свои прежние прогрессивные и художественные идеалы и превратился в обычную бродвейскую продюсерскую компанию, опиравшуюся в своей деятельности на популярность «звезд» и развлекательность.

Но время от времени «Гилд» все-таки вспоминал о своем славном прошлом и брал на себя смелость поставить что-нибудь художественное или экспериментальное. Иногда это оправдывалось и творчески, и финансово, как в случае постановки в 1943 г. мюзикла «Оклахома» П. Роджерса и О. Хаммерстейна. Он стал величайшим «смэшем», открывшим новые возможности музыкального спектакля-шоу, принесшим театру славу и миллионные доходы. Чаше же подлинное творчество денег не приносило, но способствовало сохранению художественного имиджа «Гилда» - как в случае постановки пьесы «Продавец льда грядет» Ю. О'Нила в 1946 г. Но со временем смелость «Гилда» все убывала.

Характерная для послевоенной Америки атмосфера реакции не давала развития ни общественной мысли, ни культурной жизни страны. Авторитетный литературовед Ван Вик Брукс с горечью констатировал кризис в национальном искусстве этого периода. В книге «Писатель в Америке» он отмечал обесценивание гуманистических ценностей, призывал вспомнить лучшие традиции реалистической литературы 20-30-х гг. [9]. А театральный критик Э. Бентли, как бы вторя ему, констатировал в американском театре после Второй мировой войны почти «полное угасание художественной драмы в коммерческом театре... где театр выполняет роль предыстории для будущего возрождения...» [10. Р. 16]. 
Однако именно кризис американского театра явился одновременно и началом его нового развития. В нем начинают консолидироваться силы, противостоящие коммерческой сцене. Произошло так, что монопольное господство коммерческого театра породило его альтернативу - первые некоммерческие театры. Желание театральных деятелей реализовать свои творческие силы в художественном театре привело многих из них к идее создания собственных коллективов в противовес бродвейскому театру.

Альтернативой развлекательной театральной индустрии становились коллективы, развивающие традиции национальной драматургии, режиссуры, актерского творчества, открывающие новые горизонты в сценическом искусстве. Показательно, что подобная ситуация характерна и для других видов искусств США.

Рождение движения некоммерческих театров и стало такой альтернативой бродвейскому коммерциализму, притягивавшей все новые здоровые и творческие силы американского театра. Они стали создавать свои коллективы, театры, студии, труппы, группы. Так началось движение некоммерческих театров.

\section{Литература}

1. Fergusson F. The Human Image in Dramatic Literature, Garden City. New York : Doubleday, 1957. $217 \mathrm{p}$.

2. Little St.W. Off-Broadway: The Prophetic Theatre. New York : Coward, McCann \& Geoghegan, 1972. $308 \mathrm{p}$.

3. Greenberger $H$. The Off-Broadway Experience, Englewood Cliffs. New York : Prentice Hall, 1971. $207 \mathrm{p}$.

4. Novick J. Beyond Broadway. The Quest for Permanent Theatre. New York : Hill and Wang, 1968. $393 \mathrm{p}$.

5. Langley St. Theatre Management in America. New York : Drama Book Specialists, 1974. 702 p.

6. Eaton W. P. The American Stage of Today. Boston : Small, Maynard \& Co, 1908. 468 p.

7. Helburn T. Art and Business: A Record of the Theatre Guild, Inc. // Theatre Arts Magazine. 1921. Vol. V.

8. Atkinson B. Broadway. New York : MacMillan, 1970. 564 p.

9. Brooks V.W. The writer in America. New York: Dutton, Avon, 1953. 203 p.

10. Bentley E. The Playwright as Thinker. New York : Mariner Books, 1987. 416 p.

Dmitry G. Samitov, Russian Institute of Theatre Arts - GITIS (Moscow, Russian Federation).

E-mail: goodluck@bk.ru

Vestnik Tomskogo gosudarstvennogo universiteta. Kul'turologiya i iskusstvovedeniye - Tomsk State University Journal of Cultural Studies and Art History, 2019, 34, pp. 54-60.

DOI: $10.17223 / 2220836 / 34 / 5$

THE LITTLE THEATRE MOVEMENT AND ART THEATRES IN THE UNITES STATES. THE THEATRE GUILD

Keywords: "Little" theatres; art theatres; Broadway; Theatre Guild; Theresa Helburn.

The movement of non-profit theatres in the USA appeared in opposition to commercialized entertaining Broadway at the beginning of the 20th century and reached its development in the 19101930s. Theatres of that type were called "little". At the end of the Great Depression and during the First World War the artistic and "little" theatres of the preceding decades almost disappeared.

The fighters for the new theatre knew perfectly well that the change in the quality of the American theatre was possible only with the transformation of its organizational basis, the exclusion of theatre's dependence on commerce. The entire movement experienced strong influence of the European art theaters. By the 1920s, there were already about 200 similar theatres in the United States. Among the most significant creative groups of that time one should name Theatre Guild. It was founded in 1918 as a professional team on the basis of the reorganization of its amateur predecessor, the Washington 
Square Players. It became the first professional theatre among amateur "little" theatres. It was also the first cooperative theatre, where all its members - actors, directors and managers - were equal partners who received a minimum wage and a certain percentage of the revenues generated from the ticket sales. The theatre had a Public Council.

"Guild" tried to create a permanent troupe, introduce a repertoire system and stage plays of not only the world, but also of the national drama. It was Theatre Guild that had an honor of the first productions of such plays as B. Shaw's "Heartbreak House", "Back to Methuselah", a number of plays by American playwrights - E. O'Neill, S. Howard, J.G. Lawson and others.

In the late 1920s, at the height of the theatre's popularity, it managed to attract about 30,000 season ticket holders, build its own building, organize permanent performances in the nearby cities, and not for a long time they gathered a permanent troupe of 10 artists.

By the end of the 1920s Theatre Guild moves to the position of a commercial theatre. The theatre failed to realize its hopes, as well as the potential of the permanent troupe. Having become a major theatre, it could not have prospects for the development of its artistic creativity. The main reason was the inability to achieve financial stability with a large scope of activity, incapacity for the artistic evolution of the theatre without constant material support.

Since the beginning of the 1930s, the Guild has abandoned the previously proclaimed principles, more and more faithfully following Broadway practice, differing from other Broadway theatre enterprises only by greater artistic demand. The history of this theatre confirms the impossibility of creating on Broadway an art theater with a permanent troupe and a changing repertoire.

\section{References}

1. Fergusson, F. (1957) The Human Image in Dramatic Literature. Garden City, New York: Doubleday.

2. Little, St.W. (1972) Off-Broadway: The Prophetic Theatre. New York: Coward, McCann \& Geoghegan.

3. Greenberger, H. (1971) The Off-Broadway Experience. Englewood Cliffs, New York: Prentice Hall. Wang.

4. Novick, J. (1968) Beyond Broadway. The Quest for Permanent Theatre. New York: Hill and

5. Langley, St. (1974) Theatre Management in America. New York: Drama Book Specialists.

6. Eaton, W.P. (1908) The American Stage of Today. Boston: Small, Maynard \& Co.

7. Helburn, T. (1921) Art and Business: A Record of the Theatre Guild, Inc. Theatre Arts Magazine. 5.

8. Atkinson, B. (1970) Broadway. New York: MacMillan.

9. Brooks, V.W. (1953) The writer in America. New York: Dutton, Avon.

10. Bentley, E. (1987) The Playwright as Thinker. New York: Mariner Books. 